\title{
La novela autobiográfica de Mohammed Chukri como fuente para una etnografía de la pobreza urbana en Marruecos
}

\author{
ÁNGELES CASTAÑo MADROÑAL \\ Dpto. de Antropología Social \\ Universidad de Sevilla
}

\section{RESUMEN}

El Pan Desnudo fue la primera novela del escritor marroquí Mohammed Chukri. El propio autor la ha definido como una novela autobiográfica. En ella se narran las peripecias de un chiquillo de origen rifeño que emigra con su familia desde una zona rural rifeña a Tánger, donde se ubican en un barrio marginal de la ciudad. Se plantea a través del análisis de esta obra la validez de este tipo de textos literarios como fuente etnográfica de una realidad social existente en los barrios marginales de las grandes urbes marroquíes. En el análisis se parte de la hipótesis de una etnoliteratura que nace de las fuentes literarias y permite un acercamiento etnográfico a la realidad social. La etnoliteratura se revelaría como una útil fuente de conocimiento cultural, previo al trabajo etnográfico, así como una herramienta para la comparación transcultural y el análisis antropológico.

Palabras clave: Etnoliteratura, Sociedad, Marruecos.

\section{SUMMARY}

The Naked Bread was the first novel written by Moroccan writer Mohammed Chukri. The author himself has described it as an autobiographical work, for it narrates the misadventures of a kid from the rural Rift migrating with his family to Tangiers, where they settle in a slum. The novel illustrates the passing from rural poverty to urban destitution in the Morocco of the Spanish Protectorate. By analyzing the novel, Castaño Madronal discusses the validity of literary works as suitable sources of ethnographic data for the social conditions reigning in the underprivileged areas of Moroccan cities. A parallel can be established with current rural migration to urban areas and to countries north of Morocco. The analysis builds upon the hypothesis of an ethnoliterature that draws from literary sources to approach the social reality ethnographically. Ethnoliterature can be a useful source for cultural knowledge prior to ethnographic study. It can also be a tool for cross-cultural comparisons and the anthropological analysis of social communities.

Key words: Ethnoliterature, Society, Morocco.

RDTP, LX, 1 (2005): 191-206 
Me pregunto si la escritura es una segunda autoridad tras la autoridad principal. Es un poder. Pero un poder que no es extravagante. (Mohammed Chukri: www.mundoarabe.org/...)

Por primera vez hago una modesta incursión en la literatura para, desde el análisis antropológico de una fuente literaria, realizar una aproximación a la realidad sociocultural. Para mí se trata de una experimentación, un intento de aplicar otro modo de exploración de la cultura, y un reto que afronto armada únicamente con el conocimiento que de la etnoliteratura -asignatura que impartía el profesor Manuel de la Fuente Lombo hasta su desafortunada muerte- alcancé cuando las circunstancias me obligaron con urgencia a hacerme cargo de la docencia de una asignatura troncal en la licenciatura de Humanidades, que aquel septiembre de 2001 debía haber impartido Manuel.

Distintos investigadores dedicados al estudio de la cultura desde diversas disciplinas han señalado la importancia de la literatura y de su estudio para comprender aspectos sociales y culturales que sin dichas fuentes sería difícil de vislumbrar. Incluso puede suceder que la ausencia del estudio de dichas fuentes literarias dé lugar a poco menos que deformidades culturales, si se me permite la expresión, a partir de la manera en que, faltos de informaciones complementarias, llegamos a construir idearios y percepciones sobre los desconocidos; sobre "los otros" sociales o culturales. Respecto a esta cuestión Said (1990: 342-343), señala cómo acerca del Oriente Próximo moderno, se pueden encontrar ingentes páginas escritas por expertos en Oriente sin encontrar ni una sola referencia a la literatura. El efecto de tal omisión es que se produce en la conciencia americana (y por extensión, occidental) moderna una percepción sobre el Oriente islámico y sus gentes mutilada y deshumanizada. Para Said, el conocimiento de la literatura producida por los numerosos escritores de estos países islámicos, tendría un efecto perturbador y subversivo sobre los esquemas y abstracciones con los que se representa a Oriente, porque un texto literario, en tanto que recrea experiencias y valores, habla más o menos de la realidad viva. De este modo, los arquetipos con los que hemos construido la imagen del Otro, se verían necesariamente trastocados por la humanización que la literatura -el arte en general- producen como vehículos de expresión del yo interno, esencial y existencial, imaginario pero real, ideático pero material, que desde toda cultura se reproduce a través de las creencias, valores y experiencias de sus gentes.

En este sentido, El Pan Desnudo, al que su propio autor define como una novela autobiográfica y que con las dos posteriores (Tiempo de Errores y Rostros, Amores, Maldiciones) forman una trilogía que gira en torno 
a la vida y experiencias de su autor, lo que pretende es precisamente relatar experiencias y describir un ambiente, un modo de vida de una buena parte de la sociedad marroquí en las grandes ciudades, el modo de vida que desarrolla una parte de la población que procede del medio rural y que, hasta hoy, no deja de engrosar la población urbana por el fenómeno de emigración interna rural-urbana que experimenta Marruecos desde las últimas décadas del siglo xx. Una emigración interna de la que emergen como rudos testigos los enclaves chabolísticos de Fez, Tánger o Casablanca. La novela es en cierto modo el prototipo de vida, no sólo de una generación de marroquíes a los que les tocó una coyuntura de la historia, sino de la existencia y cultura de una buena parte de los estratos de población más desfavorecidos del país, de aquellos que se ven empujados a dejar su lugar natal y desplazarse a ciudades en las que supuestamente hallarán mejores oportunidades de existencia. El propio Chukri llega a escribir:

Soy un Mohammed desconocido en la historia y defiendo a la gente que la historia oficial siempre ha olvidado. Escribo sobre individuos anónimos, porque "la memoria de los pobres de por sí está menos alimentada que la de los ricos», como dijo Albert Camús. Cuando escribo de la infancia, no se trata sólo de la mía. Se trata de aquellos que pertenecen a una generación. Así pues, no es un caso aislado sino el arquetipo de todas las infancias que he conocido perfectamente. He tratado de condensar varias infancias en una sola. Mi infancia la he escrito a través de mi mirada adulta. Es decir, no a través de las mismas sensaciones que uno siente cuando es niño. Por tanto, incluye un lado imaginario ${ }^{1}$.

La ficción narrativa de Chukri procede de una realidad vivida y de una segunda mirada sobre la misma ataviada con la perspectiva del tiempo, con la experiencia del vivir. En esta primera novela autobiográfica el autor narra su dura niñez y su cruda adolescencia que transcurre entre el Rif y las ciudades de Tánger y Tetuán. Una descripción que roza la transparencia basándose en un lenguaje sencillo, salpicado de expresiones coloquiales, en las que se recoge también el mestizaje dialectal con el español de los años del protectorado. No obstante, la realidad descrita no deja de estar bañada por la imaginación, puesto que es fundamental para entender la obra apreciar la relectura de la vida que Chukri realiza cuando, ya adulto - tras aprender a leer y escribir a los veinte añosreelabora, da sentido y recrea su propia vida. Algo que el propio autor revela cuando escribe:

Tengo dos memorias: la memoria analfabeta y la memoria de un hombre que ha aprendido a leer una vez cumplidos los 20 años (Ibid.).

${ }^{1}$ M. Chukri: http//www.mundoarabe.org/soy_un_analfabeto_antiguo_mohamed_ chukri.htm 
Estas palabras son de una sugerencia sublime. Porque, ciertamente, ¿qué extraordinario poder hay en la escritura que cuando la aprehendemos tiene la facultad de transformar incluso nuestro modo más íntimo de pensar, de racionalizar, de ordenar el universo? Cuando un niño en sus primeros años de vida acude a una escuela, es enculturado socialmente de acuerdo a un modelo sociocultural, pero además a través del aprendizaje de la escritura, desde sus primeros rudimentos, empieza a conformarse un nuevo modo de mirar el entorno. Se puede observar tomando como ejemplo el cambio que se produce en su expresión "artística", desde la expresión del ánimo y el sentido del color en unas primeras manchas abigarradas, hasta el ordenamiento de lo que el ojo observa del entorno, dando sentido racional pero perdiendo también la impronta de la espontaneidad, de la abstracción a la racionalidad. El lenguaje tiene ese poder de transformación en nuestra mente, a través de él clasificamos y ordenamos nuestro entorno, damos nombre a lo aún innombrado, identificamos lo inidentificado. Por ello, las palabras de Chukri son de indudable clarividencia, refieren a la percepción diferenciada de la propia experiencia antes y después de aprehender la comunicación escrita. Porque escribir supone una relectura de lo que se piensa, el pensamiento desordenado adquiere forma y contorno a través del ejercicio de materializarlo. Es más, adquiere una forma determinada que intencionadamente queremos dar. Por ello, el lenguaje escrito también es una poderosa herramienta que incide en la sociedad.

Ciertamente, la literatura es lenguaje escrito, y si ya de por sí el lenguaje tiene la facultad de fijar las ideas que pueblan nuestra mente, las cuales asimos y gracias a su fijación transmitimos a otros, la literatura, debido a su propiedad de fijar sobre un soporte el lenguaje, reifica ese universo ideático, lo hace material y tangible, y permite la transmisión o comunicación incluso entre lejanas generaciones de humanos, tanto en el tiempo como en el espacio, cobrando, a mi modo de ver, una importancia secundaria el hecho de la subjetividad que pesa sobre la decodificación del texto escrito realizada por el receptor. El lenguaje es una herramienta vital en la interacción humana. Si a través de él se nombra lo que existe, y nombrándolo, se clasifica y ordena todo, se puede deducir que la realidad del hombre es lenguaje y "el lenguaje es ser" (Said 1990: 245).

Como transmisora de valores, de ideas y conceptos a través del tiempo, la literatura ha jugado y juega un papel fundamental por su incidencia en la sociedad. La importancia de la literatura, crucial a partir de la aparición de la imprenta en el siglo XVII, radica en la fuerza que ha demostrado para transformar la sociedad a partir del mundo de las ideas. La literatura ha permitido no sólo plasmar sentimientos, experiencias e 
ideas, sino crear ideologías, a partir de ella se han compartido mensajes entre un gran número de receptores, aportando su vitalidad al consenso de las ideas, de los valores. Los estudios de Eagleton (1983) y Anderson (1991) sobre la importancia de la literatura en el surgimiento de la ideología nacional británica así lo demuestran. Y la obra de Said (1996) enfoca la posición de la ficción narrativa en la historia y en el mundo del imperio. Pero la revolución más importante es que el lenguaje cotidiano, la lengua materna, alcanza la redención en el mundo intelectual a través de su irrupción en la comunicación cotidiana escrita que la imprenta procuró en su momento. Todo tipo de boletines informativos, periódicos, octavillas publicitarias, etc. se imprimen en lenguaje coloquial y hasta en dialectos regionales no escritos hasta el momento. Las lenguas maternas acaban dominando la literatura, la ciencia y los escritos oficiales, transformándose en el vehículo por excelencia de aquellos valores e ideas antes transmitidos en latín, la lengua culta del mundo intelectual en Europa. Esta revolución no se produce en la literatura árabe hasta bien entrada la segunda mitad del siglo $\mathrm{xx}$, y en este sentido obras como la de Chukri han abierto la espita para la irrupción del lenguaje dialectal en la literatura árabe, pues sólo mediante esta penetración tiene cabida la narración de lo inconfesable, de lo ordinario, en culturas en las que el árabe culto ha dominado las letras, y en las que la propia escritura ha sido sacralizada como transmisora de los más altos valores culturales de la civilización árabe. En este sentido, el árabe culto ha encerrado la esencia cultural, entendiendo ésta en uno de los sentidos que Said (1996: 14-15) piensa que puede rastrearse en el análisis de la literatura, "la cultura como envase protector".

En segundo lugar, la cultura es, casi imperceptiblemente, un concepto que incluye un elemento de refinada elevación, consistente en el archivo de lo mejor que cada sociedad ha conocido y pensado, según lo formulara Matthew Arnold alrededor de 1860. Arnold creía que si no neutraliza, al menos la cultura amortigua los estragos de nuestra moderna existencia urbana, agresiva, mercantil y brutalizadora.

Las sociedades magrebíes se han caracterizado a través de distintos procesos de colonización cultural a lo largo de la historia. El lenguaje cotidiano encierra de manera manifiesta esta amalgama histórica, mientras el árabe culto ha jugado el papel de unificador de las culturas y cápsula de los valores ideales de la sociedad, por ende se ha alzado como aparato transmisor de una ideología hegemónica desde cuyo dominio, la cultura dominante se ha servido para excluir del panorama cultural las lenguas dialectales y con ellas lo que consideró culturas residuales y 
marginalizables. La importancia de la obra de autores como Chukri radica en su papel rompedor de una tónica cultural, en hacer valer una cultura transformada en alteridad endógena por la ideología hegemónica.

Por todo ello, entiendo que las fuentes literarias, aún siendo "ficciones narrativas" son tan importantes como otras a la hora de entender holísticamente una sociedad es más, probablemente, en ocasiones, acercarnos a la literatura puede suponer una manera fundamental de complementar el puzzle que nos descifre el enigma de la conducta humana en sociedad; la razón "Oculta" en el mundo de los valores, las ideas y la experiencia compartida, que nos ayude a encontrar la lógica subyacente a las acciones que nos pueden llegar a parecer más irracionales e ilógicas de la humanidad. En el mundo contemporáneo, en que la globalización parece ir acompañada de las acciones y actitudes más irracionales e inhumanas, la literatura es un foco en el que se vierten todo tipo de ilusiones, desacuerdos, fracasos, frustraciones y esperanzas. Y no sólo en la literatura sino en las artes plásticas en general, pues la pintura ha sido y es la forma en que han tomado imagen los valores transmitidos por el lenguaje, aún cuando hay que tener en cuenta que hoy la fuerza de la imagen como vía de transmisión rápida entre generaciones y culturas ha sufrido una revolución a través de las modernas tecnologías de la comunicación, y debido a ellas, su imparable incidencia en la sociedad. Pero siempre quedará la distancia entre los colectivos que tienen acceso a la manipulación y control de las tecnologías, y los que cuentan con los materiales más inmediatos para producir sus maneras de expresión y su arte, y entre éstos, el lenguaje escrito y la pintura son herramientas de acercamiento y comunicación crucial.

Margarite Yourcenar en Memorias de Adriano, señala de manera magistral la escasa "humanidad" que separa las fuentes clásicas y nuestra contemporaneidad, en una obra que torna mortal y humano a un emperador de la historia, y sorprendentemente cercanos los valores y emociones que acaban pareciendo comunes a nuestra occidentalidad.

[...] dos docenas de pares de manos descarnadas, unos veinticinco ancianos bastarían para establecer un contacto ininterrumpido entre Adriano y nosotros (Yourcenar 1998: 242).

La literatura puede crear la idea de una especie de continuum cultural, de una especie de comunión ideática entre pueblos, hasta el punto de que Adriano podría parecernos tan cercano como un vecino de nuestra comunidad, aún cuando entre su cultura y la nuestra no sólo hay un abismo ideático sino temporal. Podemos creernos más romanos y menos semitas porque la tradición escrita y oral que se nos transmite acerca a 
Adriano y aleja a Abderrahmán III. La importancia del factor literario en la reproducción cultural $-\mathrm{y}$ por ello su enorme capacidad de incidencia social-, se debe, entre otras cosas, a que el autor es producto de su época y, de manera consciente e inconsciente, a través de él se vierten en la literatura los valores y creencias de su sociedad. Incluso cuando el autor, a la manera de Chukri, utiliza la escritura como herramienta de denuncia a favor de los desfavorecidos de la sociedad, se encuentran implícitos en la obra por contraposición a lo descrito, a lo narrado, los valores hegemónicos de su sociedad.

Desde la antropología, la obra de Chukri suscitaría un debate acerca del papel de la literatura en la cultura y sobre su importancia en el estudio de la cultura. ¿Puede la literatura de una sociedad ser uno de los espejos que nos muestran las transformaciones que se producen en el seno de sus más profundos pilares culturales? ¿puede una novela más o menos autobiográfica ser fuente de estudio acerca de cuestiones de la cultura?

Me acerqué a la sociedad del norte marroquí rastreando en las historias de vida de muchos de los informantes que me contaban sus experiencias personales cuando inicié mi trabajo de campo sobre la inmigración marroquí en El Ejido. Como observadora viajé por primera vez en mi vida a Marruecos, primero, a través de los ojos de estos informantes, después, realizando observación participante con algunos de ellos en sus viajes de retorno estival o en momentos del ciclo litúrgico anual para participar en sus momentos festivo-ceremoniales.

Andando el tiempo, terminado cinco años después un trabajo de campo que ha sido mi tesis doctoral, una de las cosas que más me impactó fue la dificultad para hallar referentes de la realidad observada en muchas de las fuentes consultadas, antropológicas, del arabismo, sociológicas... ¿dónde estaban los datos etnográficos que otros autores debían haber observado antes que yo, y a los que como una tabla de salvación yo esperaba poder asirme? Hallé muchos estudios estereotipados sobre una estereotipada civilización: los espacios públicos y privados, la desigualdad entre géneros, la asignación de roles en distintos ámbitos sociales... ¿dónde estaban las etnografías sobre las relaciones de género en los lugares de marcha de la costa de Tetúan y Tánger? ¿de las jóvenes independientes con parejas de hecho que cohabitan durante los años de estudio universitario? ¿de aquella romería en que se asaban pinchitos morunos de carne de jabalí recién cazado bajo la excusa de que "no es cerdo"? ¿de los paseos furtivos de las muchachas y muchachos romeros que se internaban en la arboleda? ¿y de aquella joven universitaria de familia conservadora, emigrante en solitario en París, independiente y moderna, que tras sucesivos fracasos amorosos consultaba a un famoso vidente para hallar una respuesta de 
las fuerzas del más allá que le procurara sosiego psicológico ante el futuro? Encontré una rica sociedad diversa y plural, ensimismada en profundos cambios intergeneracionales que afectaban a los medios tradicionales del mundo rural y a la moderna ciudad. Encontré mujeres con el "velo de las rigoristas" que aspiraban a emigrar como estrategia de reafirmación personal, jóvenes modernas independientes con oficios y profesiones, insertas también en las redes políticas locales, jóvenes que hacen escapadas a Ceuta para verse con sus amigos y flirtear, jóvenes que se relacionan por internet con chico/as españoles o de otros países... Hay mucho más que aquello que los estudios "arquetipo" me habían enseñado. La literatura de Chukri abre los ojos al código de una cultura "natural", tan natural como vemos la nuestra. En los estudios sobre el Islam en Europa o en España, sobre la mudawuana ${ }^{2}$ o sobre pautas de una supuesta tradición, siempre me he preguntado si el observador especializado ha mirado a las personas, o sólo a su "objeto de estudio" para encontrar la confirmación de su hipótesis perfectamente diseñada "a priori" según los esquemas de tal o cual modelo teórico de la escuela o grupo investigador de referencia. El orientalismo como constante ideológica de los occidentales, que Said identifica en la base del encorsetamiento que sobre las culturas islámicas puede rastrearse en la mayoría de los escritos, es la única explicación plausible para que sigan diseñándose trabajos de investigación que centran su atención en aspectos culturales que son reificados en los mismos proyectos, quedando en la sombra las descripciones de las conductas humanas, las actitudes que se mueven empujadas por intereses ajenos a los códigos morales, religiosos, civiles, legislativos, desarrollando estrategias para alcanzar aspiraciones cotidianas, naturales, mundanas, aún en contra de las normas y valores aprehendidos por enculturación. En una ocasión, tratando el tema de la mirada sobre los Otros y la influencia del propio observador en lo observado, tomando el ejemplo de Marruecos, dije a mis alumnos: "una de dos: o Marruecos es una sociedad plural y diversa ideológica, cultural y socialmente, como la nuestra u otras, o desde el mismo momento en que cruzo la frontera de Ceuta y veo lo que he visto, tendría que pensar que, de acuerdo a muchas obras publicadas, toda esa masa de gente que se mueve en los espacios públicos son las putas, maricones y contrabandistas del país. Lo segundo, evidentemente, no me lo creo".

Ha sido en la novela de Chukri donde he encontrado un retrato más fiel de esa sociedad que bulle en las ciudades del norte de Marruecos. A

\footnotetext{
${ }^{2}$ Código civil basado en buena parte en la ley coránica (sharea) que rige los derechos de matrimonio, divorcio, custodia de los hijos, herencia y otros aspectos concernientes a la familia y la organización social familiar.
} 
través de esta literatura es más fácil encajar a aquel joven tangerino de catorce años que llegó a El Ejido en 1997, solo en los bajos de un camión desde Ceuta, que Hussein recogió en su casa mientras se tramitaba una regularización ficticia (como si fuera uno de sus hijos) para que no fuera a un centro de acogida, y acompañarlo después hasta Francia donde residían sus hermanos. El chico no quería seguir con sus padres en Marruecos, y nunca sabremos hasta qué punto sus padres habían estado de acuerdo con el arriesgado viaje, pues ciertamente, tampoco fueron tajantes a la hora de recriminarlo y demandar su regreso. Pero lo cierto es que tampoco se podía afirmar de él que era un "niño de la calle». Sus hermanos estaban pendientes de la tramitación de sus papeles desde Francia y se lo llevaron en cuanto el proceso estuvo concluido. Aunque en los puertos de Ceuta y Tánger pululan los muchachos controlando como vigías los movimientos de los barcos y camiones, muchos de ellos regresan a casa al cabo del día. Se sientan a una mesa más pobre que modesta, a menudo nutrida gracias a su quehacer callejero, rastreando en los cubos de basura o haciendo acopio de las sobras del zoco. Pero dudo que no se los echara en falta si desaparecieran sin dejar rastro. Muchas historias con las que me he tropezado corroboran el hecho de que las salidas de los "niños de la calle" son historias familiares, con conocimiento de causa y con estrategias de supervivencia grupal establecida.

¿Dónde se puede situar socialmente a Aicha "la leona"? La conocí desde la red masculina de tangerinos y tetuaníes de El Ejido, vivía en Adra con su marido y sus tres hijos. Su marido había conseguido traerla a España por reagrupación familiar. Su sobrenombre se debe a que era un personaje muy conocido en las redes del contrabando entre Ceuta y Tánger. Era "la leona" porque transgrediendo los roles de género se había dedicado, para sacar la familia adelante, al contrabando de alcohol, un artículo que juega un papel fundamental en el contrabando que practican los hombres. Y su fama había llegado a tal punto que tenía su propia cuerda ${ }^{3}$, formada íntegramente por hombres que trabajaban a sus órdenes. Había en el Poniente almeriense otras Aichas y el número se ha ido incrementando conforme ha aumentado la presencia de mujeres marroquíes en la zona. Como Barca, que en 1995, cuando la conocí, era de las pocas mujeres afiliadas y participativas de la asociación reivindicativa AEME-A (Asociación

${ }^{3}$ Utilizo esta designación haciendo referencia a los grupos organizados jerárquicamente para realizar el contrabando entre poblaciones fronterizas. La denominación procede de la zona fronteriza de Huelva con el Alentejo portugués, donde estuve realizando trabajo de campo en 1992, allí se utilizaba para designar a los grupos dirigidos por un capataz que a modo de trabajo en cadena pasaban el café de una localidad a otra entre los años 50 y 70 . 
de Emigrantes Marroquíes en España de Almería), y trabajaba codo con codo en las cuadrillas de hombres en los invernaderos ejidenses, y buena parte de su jornal era para sus tres hijos que estaban en Marruecos.

Los datos del Ministerio del Interior del año 2004 sobre la inmigración en Andalucía demuestran que se está produciendo un incremento considerable de la inmigración femenina, hasta el punto de que en algunas provincias no hay simplemente una tendencia a la equiparación entre los sexos sino que incluso las mujeres son predominantes. En Sevilla, las mujeres suponen el 50,2\% de los extranjeros y en Córdoba el 52,33\%. Para que esto se produzca en países como Marruecos, antes la mujer ha debido conquistar espacios de hombres en el lugar de origen. Sin su presencia evidente en la vida pública, incluso en la política, ¿cómo se puede lanzar a la otra orilla? Evidentemente, la emigración creciente de los hombres ha ido provocando poco a poco una ausencia de los mismos en las familias, con ello, una desprotección y un "desvelamiento" de las mujeres, que quedaban al frente de sus familias y debían jugar forzosamente papeles de representación social tradicionalmente vedados a su condición femenina. Incluso existen datos que muestran cómo la emigración de hombres ha provocado, en la década de los noventa, la ausencia de esta mano de obra en las zonas rurales de Beni Mellal, hasta el punto de que actualmente ni siquiera la mano de obra femenina es suficiente para sacar el trabajo agrícola adelante, siendo hoy estas zonas rurales deficitarias en fuerza de trabajo. Sin embargo, dejando a un lado estas inmigrantes de la globalización", mi trabajo de campo sobre las mujeres marroquíes en Sevilla me llevó hasta la presencia de las más antiguas residentes del vecino país africano: mujeres residentes en la ciudad desde la década de 1960, que llegaron de la mano de los funcionarios o empresarios del protectorado, mano de obra del servicio doméstico de las clases burguesas de la ciudad, pero también algunas esposas de militares españoles. ¿Hay que deducir, dados los estudios arabistas de la época, que son putas y marginales en su sociedad de origen? De acuerdo a mi propio modo de observar como antropóloga, no lo creo, ni puedo verlo así. Existen claro está, normas y valores culturales en toda sociedad, y luego, naturalmente, las personas desarrollan estrategias y conductas individuales e incluso grupales, de acuerdo a sus propios recursos explotables, a su propio capital social y simbólico, como señaló Bourdieu (1991), para alcanzar sus propios fines de reproducción física, biológica y sociocultural, o lo que es lo mismo, para alimentarse, tener hijos y educarlos de acuerdo a patrones de cultura materna aprendida. Y esto hace a las sociedades mucho más amables, más flexibles, más variopintas y menos "cosa" de lo que aparecen en los estudios realizados para mostrar cómo se ponen en funcionamiento tales o 
cuales patrones culturales de una considerada "ajena sociedad", hecha "Otra" antes siquiera de llegar a ella.

En la novela de Chukri, aparece una mujer marroquí no tan encorsetada por las normas morales de su sociedad, y no me refiero a los personajes de los prostíbulos, sino a las muchachas con las que se tropieza en su pubertad y adolescencia y con las que tiene sus primeros contactos sexuales, como el pasaje de la joven Assía y el de Fátima, la hija del propietario de la cafetería dónde lo puso a trabajar su padre (Chukri 1989: 28-32).

Aparece reflejado el mundillo del trapicheo de mercancías con los españoles, que, décadas más tarde al finalizar el protectorado, fue sustituido por el contrabando de frontera con Ceuta, del cual vive, y en ocasiones malvive, buena parte de la población de Tetuán y Tánger, pues casi 30.000 personas pasan la frontera de Ceuta a diario ${ }^{4}$, de las cuales se nutre el comercio de la ciudad, y que sirven de sustento a un buen número de población que directa o indirectamente se relaciona con este tipo de comercio fronterizo en el norte de Marruecos. Este tipo de actividad está fuertemente arraigada en la cultura popular tetuaní y tangerina, y se define con cierta constante observable en otras zonas fronterizas con nuestro país, que se podrían llegar a denominar como "culturas de frontera" ${ }^{5}$.

Mi padre compraba un saco de pan blanco y tabaco y se largaba lejos de Tánger para cambiarlo en los cuarteles a los soldados españoles. Por la tarde, cuando regresaba, traía uniformes militares que vendía en el gran zoco a los obreros marroquíes (Chukri 1989: 15).

Otros pasajes de la novela recogen personajes que en absoluto han desaparecido de los barrios populares de Tetuán.

Mi madre volvió a su negocio a vender legumbres y frutas en El Trancat y mi padre, parado, iba a la plaza Feddan, donde se reunía con los inválidos marroquíes, resultado de la guerra civil española. Algunos se vanagloriaban de ello, porque les había permitido vivir aventuras y tener recuerdos de los combates en los que participaron. Al Caudillo lo apodaban "Hadj" Franco.

Todavía hoy he podido observar a estos tullidos ya muy ancianos supervivientes de la guerra civil que formaron parte de las tropas moras,

\footnotetext{
${ }^{4}$ Declaraciones del Subdelegado del Gobierno en Ceuta en 2003, en una reunión con el consorcio de ONG, CEPAIM.

${ }^{5}$ Pautas similares de complementariedad socioeconómica observamos en un trabajo realizado entre 1991 y 1993 en la frontera entre Huelva y el Alentejo portugués. (VV.AA. 1999)
} 
que se reúnen en una explanada alta del barrio de Touilaâ (la antigua Dar Al-Khalifa), y en barrio Málaga, jugando verdaderos torneos de damas y de cartas (el juego de la ronda) especialmente en Ramadán, por la tarde, tras el rezo del laasar (el tercero del día), profiriendo palabras malsonantes en español: "granuja, te la voy a meter!; isi me la metes yo no soy un hombre con dos cojones, sino un maricón con plumas!...” y contando batallitas de la guerra, compitiendo sobre quién mató más cristianos y quién hizo la barbaridad más grande a las órdenes del "Hadj" Franco. Porque en su representación Franco es un gran mandatario de la historia, un "gran hombre", gracias a cuya generosidad ellos tenían una pensión, comían bien y habían tenido una forma de mejorar económicamente. Todavía se pueden recoger entre los más ancianos los datos etnográficos de cómo se llevaba a cabo el reclutamiento de los regulares. Durante el protectorado, el ghalmía se encargaba del reclutamiento de los varones seleccionados por edad y talla entre las aldeas rurales más pobres. El acceso a través del ejército a ropas que de ningún modo habían podido disfrutar antes, calzoncillos, calcetines, botas, uniformes relucientes, y una alimentación diaria, actuaron de revulsivo en las aldeas de origen marcadas por el hambre en plena época del protectorado, cuando tras el período de acuartelamiento e instrucción regresaban a sus comunidades con sus atavíos y su macuto de militar, produciendo tal impacto en el imaginario colectivo que desencadenaba el alistamiento masivo de los varones. El ghalmía actuaba como mediador entre el alkbalifa, máximo representante del régimen marroquí bajo el protectorado, y la administración española. El ghalmía reclutaba bajo el discurso de las ventajas económicas del alistamiento, y si quedaban dudas, lo aderezaba con hábil manejo de los códigos culturales apropiados para derribarlas, es decir, que al fin y al cabo se iba a luchar contra cristianos, que era una $y_{i b a d^{6}}$ y que con ello ganarían un lugar en el paraíso. Dicen los más ancianos que al estallar la guerra civil española, en el momento crucial en que se necesitaba un alistamiento masivo, el ejército de Franco en el protectorado arrojó varias bombas en Tetuán, una en la plaza Feddan y otras en zonas cercanas a los límites de la ciudad. Los militares españoles extendieron el rumor de que el peligro de "los rojos" había traspasado la frontera española y estaban atacando Tetuán. Los efectos del rumor fueron la indignación de las masas populares y el alistamiento masivo para la guerra civil. Sin embargo, hay que señalar que existía una posición crítica contra esta política en los sectores más cultos de la sociedad marroquí, cuya oposición a los hechos de la guerra produjo un efecto retroactivo en los supervivientes de las tropas moras cuando regresaron del frente.

\footnotetext{
${ }^{6}$ Se les llamaba así a la guerra santa, a la defensa del Islam contra los infieles.
} 
Por un lado, cierta autopercepción de marginalidad por los rumores de las barbaries cometidas y las críticas sociales que ello desencadenó, por otro, el trastorno psicológico a la hora de encajar culturalmente el papel que se había desempeñado respecto a los valores de la cultura materna. Así se puede entender cuál sería el sufrimiento psicológico de aquel personaje que acudió al conocido fkib Boukhobza, descendiente de la familia Boukhobza, conocido linaje conservador y religioso de Tetuán que mantenía una posición contra el régimen franquista y la guerra civil en su momento, para preguntarle si los ahorros procedentes de la pensión que percibía del gobierno español servían para cumplir con la obligación de ir a la Meca, pues temía caer en pecado por ser dinero procedente de cristianos. A dicha consulta el fkib respondió que el problema de dicho dinero no era que procediera de un país o un gobierno cristiano, sino que procedía de las matanzas que el susodicho personaje había cometido en su intervención en la guerra civil y que más le valía devolverlo, porque no servía ni para alimentarse con él.

Si nos vamos a otros datos históricos, aparece vislumbrada la Tánger de la época dorada de los 50, en las páginas en que se recogen las fiestas nocturnas de jóvenes tangerinos acompañados por las mujeres, el alcohol y las canciones españolas, que parecen una imitación o un reflejo a la tangerina de la vida nocturna de aquélla Tánger que los intelectuales del exilio español echan en falta, y la del movimiento intelectual de la generación beat, que dio en reunir en la ciudad a numerosos escritores extranjeros y cierto mundillo de faranduleo nocturno, que vivió en la ciudad sin vivir con la ciudad:

Nos sentamos. Nosotros dos éramos los más jóvenes. Ya habían bebido. Una chica se fue lejos al hablarle en el oído uno del grupo. La escanciadora tenía unos treinta años. Empezaron a tocar: mandolina, derbuga y pandereta eran los instrumentos. El chico que antes hablaba al oído de la chica llamó:

-¡Anisa! ¡Anisa!

Varios repitieron el mismo nombre. Llegó Anisa bailando y saludando acá y allá. Sólo llevaba una túnica muy transparente y no usaba sostén. Parecía tener el diablo en el cuerpo bailando dentro de ella. Un diablo borracho [...] (Chukri 1989: 66)

Hay muchos pasajes de la novela autobiográfica de Chukri que se pueden traer a colación como fuente documental que refleja una sociedad que se puede rastrear mediante estudio etnográfico en las ciudades de Tetuán y Tánger. La novela recoge en su ficción realista el trabajo de los niños ${ }^{7}$ que supone un complemento indispensable, cuando no el sustento mismo de las familias más pobres en los barrios marginales de la

${ }^{7}$ Ejemplos salpicados en las páginas $26,33,34,76$, y la propia vida del niño Chukri que se narra en la novela. 
ciudad. Cuando se pasea por el zoco de la medina de Tetuán y de Fez, se puede ver el trabajo asalariado, muy mal pagado, de los niños bobinadores que trabajan para los sastres, los que curten y tiñen las pieles, los que venden bolsas de plástico en los zocos, los que cargan pesadas bolsas de compra y otras mercancías a cambio de unas monedas, los aprendices de mecánica, de cerámica, de carpintería, que hacen de chicos de los recados además de aprendiz, explotados durante horas y horas al día por un mísero jornal o a cambio simplemente de tener la suerte de aprender un oficio. Y también aparecen retratados, ¡cómo no!, los "niños de la calle", ésos vagabundos urbanos que podemos ver reflejados hoy en los "niños del pegamento", que se apelotonan en las estaciones de autobuses esperando a que lleguen los de largo recorrido con las ruedas caldeadas para aspirar el vapor que emana de ellas. Es el reflejo de una cultura de la supervivencia diaria, del presente, del aprendizaje de salir al paso de las necesidades y urgencias cotidianas, de la pobreza y de la miseria urbana.

Hay un episodio en la novela que me alcanzó de lleno, porque a través de él vi representados tantos y tantos personajes reales de mi trabajo etnográfico, ésos que se quedan grabados para siempre en la memoria, porque a través de sus historias personales, sus historias de vida, encarnan profundos valores culturales. Es el episodio del suicidio colectivo:

Cada tarde, le robaba dinero a mi madre para comprarme kif y poder ir al café o al cine. Un día me encontré con un amigo. Se llamaba Tafersiti, y estaba deprimido.

- Mi tío ha muerto - me dijo.

-iPobre!

-Murieron todos: su mujer y sus tres hijos.

-Pero, ¿cómo ocurrió y por qué?

- Pasaron muchos días sin comer. No quisieron pedir nada a los vecinos. Construyó una pared dentro y murieron todos.

Este pasaje es un reflejo del rol de género masculino que encarna los valores del honor y de la vergüenza. El honor del hombre que debe ser capaz de sacar adelante a su familia y demostrar su masculinidad con el esfuerzo diario, y la vergüenza, que no sólo es del cabeza de familia, sino de la unidad familiar, cuando no se consiguen alcanzar los fines de necesidad inmediata y la miseria amenaza con dejar en la calle y la indigencia más absoluta a sus miembros. Cuando se llega a estos extremos, la unidad familiar se rompe en ocasiones por suicidio o abandono del cabeza de familia. Aunque el desconocimiento de las culturas marroquíes en España y lo reciente del fenómeno inmigratorio en nuestro país no ha dado lugar a establecer beneficiosas conclusiones a nuestros ciudadanos, 
vale la pena traer a colación la publicidad que una entidad bancaria de origen británico, Citybank, llevó a cabo a través de distintas ONG en Sevilla, ofreciendo facilidades de acceso para inmigrantes a sus préstamos hipotecarios. Probablemente, la experiencia británica ha demostrado a la entidad bancaria que el concepto del honor en determinados colectivos se refleja en pautas y conductas encaminadas a hacer lo imposible antes de dar signos externos de no poder mantenerse en niveles dignos de vida. Por tanto, antes de perder la vivienda y terminar bajo un puente, antes de perder la dignidad, se puede preferir perder la vida. Me hizo recordar también a aquel joven veinteañero tetuaní que cuidaba de sus cuatro hermanos menores, los alimentaba, aseaba, vestía y protegía a diario, como una madre o como el padre que los había abandonado en su miseria un día lejano.

En una ocasión, recorriendo los desastres del terremoto de Alhucemas en la zona olvidada de la política y de los medios de comunicación, más allá de la zona declarada catastrófica, que no sólo padecía los efectos de la catástrofe sino que después quedó fuera de la intervención gubernamental y de las actuaciones de las ONG de cooperación internacional, en Terguist, un veterano cooperante español de una asociación de Sevilla, con una larga experiencia de vida también con las clases desfavorecidas en Andalucía, me hizo la siguiente reflexión: "lo malo de la emigración de estas gentes a la ciudad es que dejan una pobreza digna para alcanzar la miseria urbana”. Quizás por eso, hoy, en las raras ocasiones en que en las aldeas de origen la vida parece mejorar, ahora que empieza a llegar la luz eléctrica, las madrasas ${ }^{8}$ se acercan al campo y los autobuses de línea te llevan del campo a la ciudad, algunas de estas aves tornan a sus nidos.

\section{BIBLIOGRAFÍA CITADA}

ANDERSON, B. 1991. Imagined communities: Reflections on the origin and spread of nationalism. Londres: Verso.

BOURDIEU, P. 1991. El sentido práctico. Madrid: Taurus.

CHUKR, M. 1989. El pan desnudo. Barcelona: Montesinos.

— "Soy un antiguo analfabeto". http://www.mundoarabe.org/soy_un_analfabeto_antiguo_ mohamed_chukri.htm

EAGLETON, T. 1983. Literary theory: an introduction. Minneapolis: University of Minnesota Press.

${ }^{8}$ Colegios públicos laicos que se han construido también en las zonas rurales con la función fundamental de alfabetizar la población rural. 
Hernández, E., A. CASTAÑo, V. Quintero y R. CÁCeres. 1999. Fiesta y frontera. Transformaciones de las expresiones simbólicas en la franja fronteriza de Huelva. Sevilla: Consejería de Cultura de la Junta de Andalucía.

SAID, E.W. 1990. Orientalismo. Madrid: Libertarias.

- 1996. Cultura e imperialismo. Barcelona: Anagrama.

YourCENAR, M. 1988. Memorias de Adriano. Barcelona: Orbis. 